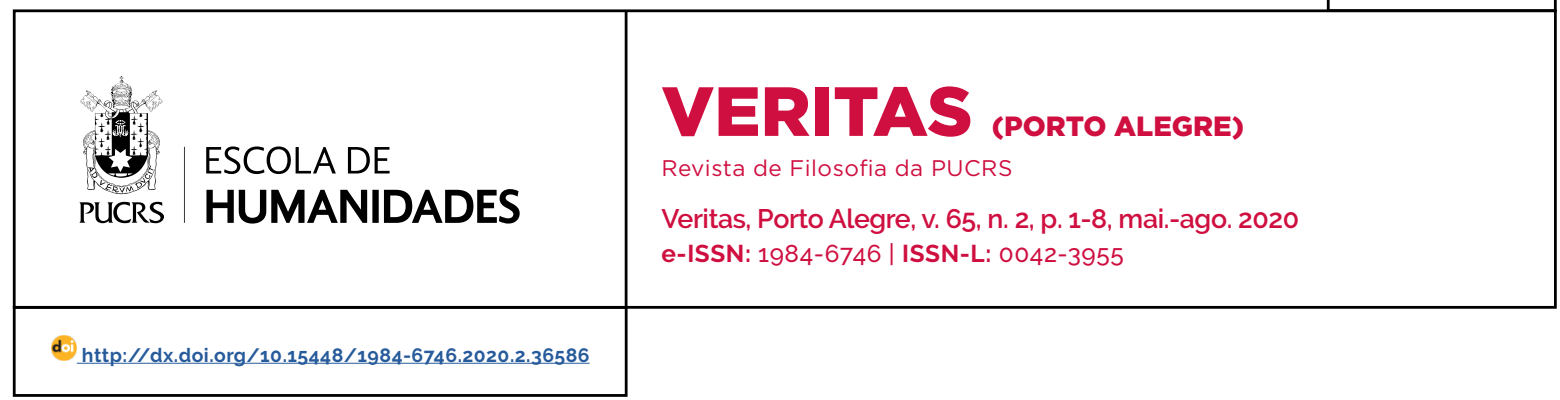

SEÇÃO: TRADUÇÃO

\title{
Hermenêutica, Democracia, Emancipação
}

\author{
Hermeneutics, Democracy, Emancipation
}

Hermenéutica, Democracia, Emancipación

\section{Gianni Vattimo}

\section{Tradução de Gabriel \\ Debatin $^{2}$}

orcid.org/0000-0003-1139-0115 gabrieldebatin@gmail.com

Recebido em: 3 fev. 2019 Aprovado em: 24 fev. 2020. Publicado em: 28 jul. 2020.

\section{(c) (1)}

Artigo está licenciado sob forma de uma licença Creative Commons Atribuição 4.0 Internacional.
Pode-se "fundar" uma politica democrática, de emancipação, ou ainda, dizendo mais claramente, progressista e de esquerda, sobre a hermenêutica? Ponho a questão em termos brutais, ou quase, precisamente para não encobrir seu caráter imediatamente escandaloso. A hermenêutica é uma filosofia que, no melhor dos casos, apresentase como politicamente "neutra", embora muito atenta para não repetir os erros dos "fundamentalismos" filosóficos do passado, que dentre outras coisas pretenderam frequentemente indicar caminhos para a emancipação humana ao conclamar para si ou um suposto conhecimento da essência do ser humano, ou um ponto de vista privilegiado sobre a teologia própria da história. Para os seus adversários, pelo contrário, essa atitude politicamente neutra da hermenêutica é comumente identificada, pura e simplesmente, como uma forma de conservadorismo: recorrência à tradição, "reabilitação do pré-juízo" (como diz Gadamer explicitamente), desconfiança em relação à ciência e à técnica, bem como um permanente vínculo com a cultura humanística, uma negação de qualquer critério "objetivo" de verdade, e consequentemente a relegitimação do mito, da religião, e até, quem sabe, de esoterismos...

Mas não se trata aqui apenas de responder a tais criticas, que até este ponto poderiam muitissimo bem ser consideradas externas ao verdadeiro significado filosófico da teoria hermenêutica; nem se trata de conferir a elas um peso mais determinante porque estamos falando num ambiente onde a questão da relação entre a filosofia e as suas implicações políticas (conservadoras ou revolucionárias) é particularmente percebida por razões muito evidentes, mas não estritamente teóricas. O fato é que o problema da relação entre hermenêutica e democracia, ou programas politicos de emancipação, é uma questão que toca a própria substância da hermenêutica como filosofia. O que pretendo defender é que, se a hermenêutica não responde às perguntas sobre a emancipação, isso não depende de sua fidelidade à sua vocação teórica especifica - que, quer enquanto filosofia consciente de seus próprios limites, quer como

\footnotetext{
Do original: Ermeneutica, democrazia, emancipazione. VATTIMO, 1999, pp. 1-19. [Todos os colchetes ao longo do texto são do tradutor] 
filosofia da interpretação, que não quer confundirse com o velho fundacionalismo metafísico, pelo que lhe é exigido de não entrar no terreno político com os seus instrumentos teóricos. A recusa de "compromisso" com a questão da emancipação, creio, significa uma insuficiência do próprio discurso teórico da parte da hermenêutica. A hermenêutica, como procurarei demonstrar, encontra-se em uma espécie de impasse; tornouse uma filosofia de limites muito amplos, cujos princípios (cada experiência de verdade é um fato interpretativo, com tudo aquilo que daí decorre) são mais ou menos aceitos por quase todas as correntes filosóficas de hoje; tanto que eu acredito ser possivel falar da hermenêutica como nova koiné, o novo idioma comum que. a partir do final dos anos setenta, substituiu a hegemonia do marxismo e, posteriormente, do estruturalismo, como pano de fundo de todos os nossos discursos e debates. Mas tornando-se uma koiné, a hermenêutica também perdeu quase completamente qualquer fisionomia reconhecivel: é isso que se vê, por exemplo, se considerarmos certos manuais publicados nos últimos anos, que põem sob a categoria da hermenêutica quase tudo aquilo que, na linguagem filosófica anglosaxônica, é chamado de filosofia continental, e que nos decênios do pós-guerra se chamava existencialismo ou fenomenologia. Ora, de uma tal condição de vagueza e, para dizer tudo, de frivolidade e vazio, a hermenêutica pode libertarse apenas se refizer as exigências originárias que the inspiraram os autores, especialmente Heidegger, que a caracterizaram; mas para uma tal revisão - um verdadeiro e legítimo exame de consciência, por assim dizer - é preciso que ela seja propulsionada hoje ainda e sobremaneira em relação aos problemas políticos e éticos aos quais, nos decênios passados, não considerou ser um dever pensar. Pode bem ser que a desatenção da hermenêutica ante os problemas da política e da emancipação fosse justificada, até poucos anos atrás, ou por motivos teóricos internos (tratava-se primeiramente de combater no plano da teoria o fundacionalismo metafísico; e diria que esse é especificamente o sentido de um trabalho como aquele de Rorty, a partir da Philosophy and the Mirror of Nature [1979]), ou por conta de condições culturais e sociais em que, diante da persistência de políticas totalitárias que se apresentavam como atuação de programas filosóficos (o marxismo, obviamente), ocorria insistir sobretudo nas caracteristicas pragmáticas da política: em suma, foram anos em que era "justo" afirmar o caráter não político da filosofia e o caráter não filosófico da política. Hoje, e certamente aqui sou condicionado pela perspectiva da situação italiana, creio que há amplas analogias com a situação dos outros paises industriais avançados (e talvez também, diversas em alguma medida, com a situação das democracias latino-americanas), tanto por motivações teóricas internas (o impasse e a generalidade em que a hermenêutica parece se encontrar), quanto pela situação social e cultural geral (certamente para mim a italiana e a europeia), que parecem requisitar que essa separação entre a filosofia e a problemática política da emancipação seja posta em discussão.

Já estas observações de partida poderiam ser objeto de ampla discussão; e espero que se possam aprofundar neste nosso debate. Pretendo agora proceder procurando mostrar em que sentido, pondo-se mais francamente o problema da emancipação, a hermenêutica não apenas não trai as próprias premissas, mas pelo contrário, dá um passo decisivo na direção da solução dos problemas nos quais, como koiné, parece ter se desenvolvido.

Quando falamos de hermenêutica, creio que todos mais ou menos entendemos uma posição filosófica que pode se definir mediante dois termos: (a) abandono do fundacionalismo metafisico (isto é, da filosofia dos primeiros principios: Aristóteles; mas também: da filosofia como conscientemente posta à luz das condições de possibilidade da experiência e da ciência: de Kant ao neopositivismo e à fenomenologia); (b) concepção do mundo como conflito de interpretações. Esses dois traços constitutivos da hermenêutica são claramente homólogos (no sentido em que falou de homologia entre filosofia e sociedade o autor chamado Lucien 
Goldmann) com as caracteristicas que definem a modernidade na descrição clássica de Max Weber: tanto a dissolução do fundacionalismo quanto a liberdade do conflito de interpretações são correlatas, quiçá efeitos mecânicos, da pluralização das esferas da existência e dos sistemas de valor que se verificam no mundo moderno. Até mesmo a "microfísica do poder" de Foucault - que, contudo, considera que se deva falar ainda de poder no singular, como se fosse um agente de algum modo único em relação ao qual, por oposição, define-se cada atividade de emancipação - é, na verdade, uma confirmação do fato de que, na pluralização das esferas da existência, não se dá mais uma "racionalização central" (e talvez justamente por isso os sistemas disciplinares devem tornar-se mais explícitos, ramificados, acabando por se tornarem mais rígidos). Mas, para permanecer mais um pouco no tema da relação social da hermenêutica, a mesma sociedade que se caracteriza como pluralidade de linguagens e sistemas de valores irredutiveis a uma racionalidade central e como lugar de conflito de interpretações, livres de qualquer pretensão realístico-metafísica, parece hoje aquela na qual não se consegue mais desenvolver qualquer projeto político de emancipação. Decerto, lá, onde as condições do livre jogo de interpretações são ainda gravemente precárias - sociedades autoritárias, regimes de exploração colonial ou algo próximo disso -, uma política filosoficamente inspirada tem diante de si a tarefa de estabelecer ou restabelecer as mínimas condições da democracia liberal. Mas aquilo que se verifica hoje, frequentemente, nas sociedades industriais avançadas, é que de fato as condições do pluralismo e do livre diálogo social são largamente efetuadas, e se torna sempre mais urgente decidir, ainda e propriamente com a ajuda da filosofia, que coisa quer-se ai dizer, como concretos partícipes do diálogo, uma vez que este seja, de saída, possivel. É fato que posições como a teoria do agir comunicativo nos convidam a desconfiar das distorções e manipulações as quais, nas sociedades liberais, o diálogo social parece ainda estar sujeito; dessa forma, o programa de instituir uma efetiva pluralidade e uma autêntica possibilidade de conflito de interpretações parece ser uma tarefa sempre atual (e, talvez, interminável). Mas essa atitude de desconfiança crítica traz consigo um grave risco, que gera muitas dúvidas sobre o binômio éticapolítica, do qual deriva: se, ainda que na ausência de associação, nós continuamos a suspeitar que a comunicação social seja manipulada e distorcida (por causa da mídia de massa, da publicidade etc.), será difícil não admitir que quem está em condições de desvelar a distorção (quase) universal da comunicação é apenas uma elite, um grupo de intelectuais "puros", um comitê central ou uma vanguarda de classe que se mantém miraculosamente subtraída das manipulações... A hermenêutica, de sua parte, não pode levar a sério isso que os seus interlocutores de fato dizem, considerando-se um interlocutor dentre todos os outros; e isso porque, ao invés de assumir a posição de um supremo juiz das condições ideais do diálogo, deveria decidir o que de concreto tem para dizer.

Como disse acima, nas sociedades em que certas condições básicas do diálogo são realizadas e cujo "mundo" de fato se configura como um conflito de interpretações, parece que a projeção social e política tenda a extinguir-se; é como se a Babel das línguas em que se encontra acabe por desativar qualquer vontade crítica efetiva. A essa situação, as sociedades tardoindustriais tendem a reagir com uma renascença de fundamentalismos de vários tipos, desde aqueles étnicos até aqueles religiosos, familiares ou genericamente comunitários. Politicamente, de resto, verifica-se uma (nem tanto) paradoxal aliança entre grupos neoliberais (os reaganianos, para dizer às claras) e os fundamentalistas: ambos, por motivos diversos, têm interesses em afrouxar os laços sociais, como se vê no caso dos subsidios estatais para escolas privadas. Os liberais as favorecem à medida que as veem como uma extensão dos principios da livre iniciativa (e também porque a educação se torna um business...); já os fundamentalistas de vários tipos as veem como uma oportunidade 
de se encarcerarem nas suas ortodoxias, sem terem de se confrontar com uma sociedade verdadeiramente aberta e dialógica.

Não pretendo desenvolver mais longamente esta análise "política" - embora, como disse, não creio que ela seja tão heterogênea aos interesses a às tarefas da filosofia. Quero apenas sublinhar que essa situação das sociedades industriais avançadas, onde a liberdade do conflito de interpretações anda ao lado de um tipo de queda de tensão na capacidade de projeção social e com a renascença reacionária dos fundamentalismos, parece-me uma espécie de representação analógica do impasse em que penso se encontrar a hermenêutica filosófica. Como disse, os dois traços constitutivos da hermenêutica - o abandono dos fundamentos e a liberdade dos conflitos de interpretação - são também as características com as quais podemos descrever aquilo que acontece nas democracias industriais avançadas, na atmosférica babélica da sociedade de mercado e na correlata afirmação de identidade comunitária restrita que tendem a jogar aos ares qualquer coordenação, e a produzir fenômenos de dissolução do vínculo social. Talvez Nietzsche constatasse isso similarmente quando dizia que "não somos mais materiais para uma sociedade". Pode a hermenêutica limitar-se a acompanhar esses fenômenos dissolutivos, anárquicos, mas que, pelo que parece, preparam apenas o renascimento dos mais graves conflitos entre os fundamentalismos opostos? O que quero dizer é que a hermenêutica hoje parece demasiadamente pouco niilista, num sentido radical, para realizar de fato esse sonho "anárquico" de Nietzsche. Procuraremos ver por quê, bem como delinear um percurso teórico que ponha a hermenêutica em condições de responder melhor tanto à sua própria vocação especíica como teoria, quanto às perguntas que the vêm da ética e da política.

A hermenêutica não pode reduzir-se totalmente em antifundacionalismo acrescido da liberação dos conflitos de interpretação, porque se assim fizesse, trairia a sua inspiração de fundo. (É óbvio que não há nenhuma razão pela qual uma filosofia não deveria trair a sua inspiração originária; mas não parece ilegítimo recorrer a essa inspiração originária justamente no momento em que, por razões internas e externas (como as sociais e politicas) a teoria parece ter chegado a um ponto morto...). A inspiração originária da hermenêutica como argumentei algures - consiste na refutação heideggeriana da metafísica, isto é, daquele pensamento que identifica o ser "verdadeiro" (o ontos on de Platão e Aristóteles) com a objetividade determinável, mensurável e manipulável dos objetos da ciência-técnica moderna. Essa recusa de identificar o ser com o ente, por sua vez, é motivado por razões não puramente teóricas, mas por exigências ético-políticas, que Heidegger compartilha com as vanguardas filosóficas e artísticas da primeira metade do século XX (penso, por exemplo, em Geist der Utopie [1918], de Ernst Bloch). A identificação do ser com a objetividade manipulável dos objetos da ciência-técnica é vista como premissa da inevitável transformação da sociedade naquela que, mais tarde, porém na mesma linha, Adorno chamará de organização total. O que importa aqui, para entender a originária inspiração heideggeriana da hermenêutica, é que Heidegger não pode, sem contradizer-se, rejeitar a metafísica (a identificação do ser com a objetividade; isto é: o esquecimento do ser) por motivos teóricos. Não pode, então, defender que a concepção metafísica do ser é falsa, não é exata, não é conforme aquilo que verdadeiramente, "objetivamente" o ser é. Procedendo assim, procuraria apenas uma noção do ser mais adequada ao seu modo objetivo de dar-se; e dessarte o identificaria mais uma vez com um ente presente, um objeto, etc. É assim também que se abre a via ao antifundacionalismo da hermenêutica: esta não se propõe ser uma teoria que "funda" a própria validade sobre a demonstração, como prova, de uma estrutura qualquer estavelmente dada do ser, à qual se poderia depois adequar-se igualmente na prática. Como escreve Nietzsche, "não há fatos, apenas interpretações"; mas também essa frase, precisamente, não é a enunciação de um fato, é "apenas" uma interpretação. A hermenêutica se mantém fiel à sua inspiração 
de base e alcança o seu significado mais próprio apenas se desenvolve todas as implicações dessa observação de Nietzsche. A primeira destas implicações é que a hermenêutica não poderá apresentar-se (somente) como a (meta)teoria da pluralidade das interpretações - porque isso seria ainda um tipo de posição metafísico-descritiva. Mas então o quê? Deste impasse - que é além disso a razão de uma certa perda de peso da hermenêutica que se tornou koiné - se sai, creio eu, reconhecendo-se que a hermenêutica não é apenas antifundacionalismo mais conflito de interpretações, mas implica uma filosofia da história - ainda que entendida somente como filosofia da história do fim da filosofia da história. Com essa expressão um pouco artificiosa, pretendo dizer que quem, como por exemplo Lyotard, declara o fim das metanarrativas, das grandes narrações, se não quiser que essa declaração seja uma enésima tese metafísica (não há metanarrativas, elas não correspondem ao estado dos fatos etc.), deverá argumentar precisamente (e apenas) com base em uma narrativa da consumação e dissolução das grandes narrações. A filosofia da história do fim da filosofia da história, da qual a hermenêutica deve recordar-se se não quiser representar-se como tese metafísica, não poderá ser uma história da consumação do ser metafísico. Esse ser, de fato, não é negado por uma teoria que o reconhece objetivamente como diferente, não identificável com os objetos; mas apenas por uma narrativa que o mostra como "não mais sustentável", uma mentira reconhecida como tal porque não é mais solícita ou necessária. É, como se entenderá facilmente, a lógica da "morte de Deus" anunciada pelo Zaratustra nietzschiano: não a tese (metafísica) "Deus não existe"; mas a enunciação narrativa: "Deus, cuja ideia serviu para criar condições de maior segurança e fazer o ser humano sair da selva primitiva, é hoje uma hipótese demasiadamente excessiva, incômoda, não mais necessária; e isso porque ela atingiu seus objetivos, de estabelecer segurança, sociabilidade regulada, etc.".

A verdade da hermenêutica - seja sua inspiração originária, seja a mera possivel motivação de sua validade como teoria - se associa, então, a uma visão da história da nossa cultura, e do sentido do ser nela, como processo de dissolução das estruturas fortes; ou, com o termo de Nietzsche, como advento do niilismo, isto é, de uma situação em que, segundo a expressão de Heidegger em referência a Nietzsche, "do ser como tal não resta senão nada".3 Reconhecendo-se inseparável de uma filosofia da história marcadamente niilista, a hermenêutica não se limita mais a teorizar, de maneira meio vazia, o mundo como conflito de interpretações livre de qualquer metafísica (exceto uma: aquela que precisamente descreve o mundo como conflito de interpretações). Mas propõe as suas "teses" como interpretações argumentadas do êxito de um processo no qual se encontra envolvida e no qual, justamente por isso, não pode não firmar posição, despertando no decurso do processo mesmo um fio condutor que as inspiram escolhas, projetos, juizos. Note-se que esse sentir-se "unterwegs", e por isso na condição de dever firmar posições, não apenas contempla, descreve, desvela condições de possibilidade, mas corresponde perfeitamente à ideia heideggeriana que o ser-ai existe como projeto lançado, e que, por conseguinte, o pensamento não é uma mimética "objetiva" de um mundo externo. Também o "dever" da hermenêutica de não se colocar como observante "neutra" nos confrontos da política e dos projetos de emancipação, em análise última, depende disso.

Uma explícita filosofia da história é necessária à hermenêutica para não trair sua própria aspiração originária, recaindo de uma só vez na metafísica, da qual quis sair, e na vacuidade de uma "filosofia da cultura" relativista. E uma filosofia da história é ainda aquilo que sempre precisaram, ao menos na sociedade moderna em que as massas tomaram a palavra, todos os movimentos políticos de emancipação (convidolhes a repensar a dimensão decisiva daquele breve escrito de Walter Benjamin intitulado Teses sobre a filosofia da história [1940], salientando que seria equivocado considerá-lo apenas como uma crítica negativa de qualquer filosofia da história).

3 Nota do tradutor: Es mit dem Sein selbst nichts mehr ist. 
Hoje as filosofias da história que de fato inspiraram os movimentos políticos revolucionários (falidos) do nosso século (o século $X X$ ) se tornaram insustentáveis; mas, também isso, não porque se reconheceram "objetivamente falsas"; mas porque se sucederam menos condições favoráveis daquelas que as regiam no âmbito social e ideológico; não se pode mais conceber a história como um curso unitário - ou seja, eurocêntrico nem a cultura humana como a realização de um modelo universal de ser humano - mais uma vez, o humano ocidental moderno. Com isso, porém, não é apenas tornado livre o campo pelo qual qualquer um possa fazer valer sua interpretação do mundo. Se o conflito das interpretações não deve ser uma luta física e a imposição do mais forte (coisa que seria novamente uma forma de exaltação metafísica da objetividade, o emprego do fato, da força, como faz o direito), é preciso que as interpretações ofereçam argumentos. O movimento político de emancipação parece afim à hermenêutica nisso: nunca foi possivel oferecer argumentos metafísicos, provas baseadas nas estruturas de fato, mas apenas argumentos geschichtsphilosophisch, de filosofia da história. É fato que no passado posições políticas revolucionárias se apoiaram em teorias dos direitos "naturais", assim como em filosofias existencialistas. Mas talvez a falência daquelas revoluções (também o proletariado marxista pretendia ser o portador do sentido "verdadeiro", não ideologicamente falseado, da história...) se explica com estes resíduos metafísicos ainda não superados. Hoje, contudo, essa fundação "jusnaturalista" da política progressista não é mais possivel: seja porque não podemos renunciar à crítica da ideologia, que nos pôs definitivamente em guarda contra a fundação dos direitos sobre supostas essências, seja porque, sobretudo e isso é um sinal de que o fim da metafísica vem com o trazer a lume das suas implicações extremas - a invocação da "natureza" (inclusive das diferenças "naturais" entre povos, raças, individuos, etc.) se tornou um patrimônio da política de direita, que se revela assim por aquilo que é: uma exaltação da ordem existente como norma "natural" a ser respeitada e promovida em todas as suas implicações (liberar a concorrência econômica das amarras e grilhões do "stalinismo" é um claro exemplo disso...).

O que oferece, então, uma hermenêutica entendida como filosofia da história niilista à política democrática e aos movimentos emancipatórios? A substância da filosofia da história que a hermenêutica deve reconhecer como seu conteúdo central por excelência, repetimo-la, é esta: (I) a ideia de que a única racionalidade de que dispomos, para além do fundacionalismo metafísico, é uma racionalidade "histórico-narrativo-interpretativa". Isso, então, afirma sua própria validade sem exibir fundamentos, mas narrando e interpretando de certo modo as vicissitudes da cultura que todos os interlocutores têm em comum, e, assim, a história mesma da modernidade. (II) Tais vicissitudes, assumindo-se todos os riscos que estão conectados a uma generalização deste tipo, a hermenêutica as interpreta segundo um fio condutor, não determinístico porque reconhecido apenas a posteriori e sem quaisquer pretensões de previsibilidade, que chamamos "niilismo" porque compreende a história da modernidade como um processo de dissolução, em múltiplos niveis, de qualquer estrutura forte: secularização da tradição religiosa, secularização do poder político, dissolução da "ultimidade", ainda que ao interno do sujeito (tome-se a psicanálise como exemplo disso), fragmentação de qualquer racionalidade "central" com a multiplicação das ciências especiais e a sua irredutibilidade tendencial a um esquema unitário, pluralização dos universos culturais em oposição a uma ideia de um curso unitário da história humana... Todos os aspectos do processo niilista da modernidade que poderiam ser ilustrados, para além dos expressos nos textos de Nietzsche, com autores como Max Weber, Norbert Elias, René Girard, e como tantos romancistas e poetas do século XX - de Proust a Musil, e seguindo também os diretores de cinema como Fellini. Como se vê, estamos quase na banalidade: é a situação espiritual em que todos de fato vivemos. Importa, 
porém, a interpretação filosófica que se confere a ela, e as implicações que, ainda sobre o plano da projetividade política, nos possa trazer.

Pulando algumas passagens intermediárias, procurarei enunciar, em conclusão e sem construir nexos sistemáticos, alguns pontos da resposta quea hermenêutica entendida como ontologia e filosofia niilista da história tem a oferecer à pergunta éticopolítica acerca da democracia e da emancipação.

(I) O ideal de igualdade, que ao longo de muito tempo dominou os movimentos políticos progressistas, foi substituído pelo ideal da redução da violência. Entende-se claramente o porquê: a igualdade é sempre mais uma tese metafisica que se apresenta como tal para ser refutada pela crítica da ideologia: enquanto possui a pretensão de versar sobre uma essência humana dada de uma vez por todas, expõe-se, dentre outros, ao risco de reduzir a história e a diversidade entre as culturas à pura errância, ou ao risco de ver-se num processo que tende a realizar um ideal já dado e fornecido por rígidos significados normativos. Além disso, pense-se o quão pouco, hoje, a ideia de igualdade pode valer, quer ante aos riscos da homologação de fato que ameaça as sociedades tecnicamente avançadas, quer ante à consciência, que se vai difundindo, dos limites do "especismo", já que o valor da igualdade está estritamente ligado, na tradição, à ideia de que o ser humano é diferente dos animais. Por outro lado, uma interpretação da história da modernidade em termos de dissolução das estruturas fortes do ser põe a claro o fio condutor da redução da violência, entendida não como violação do direito de cada "essência" ao seu "lugar natural", mas como afirmação peremptória de uma ultimidade que, como o fundamento metafísico (ou ainda como o Deus dos filósofos), não admite questões ulteriores sobre o porquê. pois interrompe o diálogo, silencia.

(II) Uma visão similar da história como redução da violência, dentre outras coisas, abre também o caminho para incluir, em um projeto político de emancipação hermeneuticamente inspirado, as várias instâncias do ecologismo contemporâneo, que podem ser reconhecidas, e ainda delimitadas, do ponto de vista do fio condutor da redução da violência (contra a natureza, sobretudo). O ideal de redução da violência é um télos que se nos avizinha assintoticamente e, portanto, evitando aquelas violências que seriam fatalmente reivindicadas no caso de uma tentativa de eliminação completa e imediata de qualquer violência. Ainda posso comer carne, por exemplo, mas começo a não sair para caçar por diversão ou para produzir pelúcias carissimas...

(III) A insistência sobre o valor da igualdade não tem muito a opor àquilo que a cada vez de modo mais claro, hoje, torna-se o valor central dos partidos políticos conservadores e de direita, e dessarte da exaltação da concorrência e da competição, em todos os níveis da vida social, como garantia de "desenvolvimento". Uma sociedade fortemente concorrente não contrasta necessariamente com os princípios da igualdade, mas, todavia, dificilmente a definiremos como uma sociedade democrática, humana, conforme ao ideal da emancipação. Essa contradição, contudo, se desfaz diante do "princípio" da redução da violência, que constitui um limite bem mais liquido à exaltação da competição e, também, da ideologia do progresso a quaisquer custos.

(IV) O principio da redução da violência traz consigo, inclusive, a possibilidade de assumir posições não genéricas, mas nem por isso, porém, contraditórias, em relação aos dois aspectos que, na hipótese aqui proposta, são características surgidas das sociedades industriais avançadas: a cultura do supermercado e o fundamentalismo reacionário que a ela se opõem. A cultura do supermercado é um pluralismo sem orientação niilista, que ignora o fio condutor da redução da violência: em seu nome, muito mais racionalmente que com as perspectivas existencialistas do papa (João Paulo II), pode-se repudiar o consumismo exasperado, o voto dos significados existenciais, o tédio da sociedade opulenta geradora de compensações violentas. É sempre o fio condutor da redução da violência que vale como principio para a crítica dos fundamentalismos reacionários que acreditam vencer a Babel do supermercado ao reencontrar identidades fortes, paternidades 
tranquilizantes e, ao mesmo tempo, ameaçadoras. A dissolução moderna das metanarrativas universalistas não tem o sentido de reabrir a estrada às pertenças e às identidades em termos de etnias, familias, raças, igrejas etc.

(V) Talvez essa questão da identidade local toque num dos verdadeiros pontos fracos do movimento político de emancipação fracos tanto no plano da persuasão da sua imagem, quanto de sua coerência teórica. Os movimentos democráticos permanecem ainda hoje constantemente tentados por ideais comunitaristas, que, a bem ver, como o valorigualdade, têm raiz na insistência em posições metafísicas. À natureza humana, segundo essa perspectiva, não compete apenas a igualdade. mas também a pertença às comunidades naturais que são postas em perigo pela fragmentação moderna e pelo surgimento de vínculos sociais não convencionais etc. Esse comunitarismo naturalístico faz com que ainda hoje o pensamento democrático olhe com suspeita o mundo que Marx chamou de prostituição generalizada: o mundo da fantasmagoria do produto, da hýbris experimental em que pensava Nietzsche quando falava do Übermensch. Talvez não seja apenas um caso ligado às contingências locais que fizeram com que o movimento progressista italiano, nos últimos tempos e sobretudo nas últimas eleições (o autor se refere aqui diretamente à figura de Silvio Berlusconi e seus correligionários neoliberais), tenha parecido - e tenha sido, na realidade - assumir uma posição política "conservadora", ou ao menos demasiado prudente e cautelosa em relação às grandes transformações (constitucionais, econômicas), que, ao contrário, constituiam o programa das forças tradicionalmente "conservadoras". Pode parecer paradoxal, mas precisamente a adoção de uma perspectiva niilista pode dar à política democrática a capacidade de ver a fantasmagoria do mundo pós-moderno de maneira não simplesmente defensiva e reacionária. Talvez devido a um pouco de bom senso (como é, por exemplo, questão de bom senso que na Itália e na Europa a esquerda democrática deva confortar a classe média para fazer-se aceitar como possivel partido de governo) foram excluidas do âmbito dos seus programas as tantas propostas, outrora ditas "delirantes", que circulavam no final dos anos sessenta junto a autores como Deleuze e Guattari, ou ainda as muito menos perturbadoras ideias sobre a revolução "estético-instintiva" de Marcuse. O esforço de repensar a emancipação à luz de uma filosofia da história de pegada niilista poderia possuir também o sentido de recuperar, paradoxalmente, mas não tanto, as dimensões utópicas que tão precipitadamente nos conformamos em descartar, deixar de lado.

\section{Referências}

VATTIMO, Gianni. Ermeneutica, democrazia, emancipazione. Carte Italiane: A Journal of Italian Studies, Los Angeles, University of California, v. 16, p. 1-19, 1999.

\section{Gabriel Debatin}

Doutorando em Filosofia pela Universidade Federal de Santa Catarina.

Professor do Departamento de Ciências Humanas da Universidade Tecnológica Federal do Paraná.

\section{Endereço para correspondência}

Gabriel Debatin

Universidade Tecnológica Federal do Paraná

Via do Conhecimento, 01, Bloco L, sala 102

Fraron, 85503-390

Pato Branco, PR, Brasil. 